\title{
Telegram of Condolence to Professor Wang Bo, the Chair of the Philosophy Department of Peking University
}

We were shocked to learn of the passing yesterday of Professor Tang Yijie and are incomparably grieved. Professor Tang and [his wife] Professor Yue Daiyun received honorary doctorates from our university in 2006 and guided us in our research. Many of our faculty members and graduate students visited your department and engaged in advanced studies, receiving enthusiastic guidance from Professor Tang and other professors. We earnestly express our heartfelt thanks and extend our sincerest condolences.

\author{
KUSUMI Harushige \\ President of Kansai University \\ Osaka, Japan \\ September 10, 2014
}
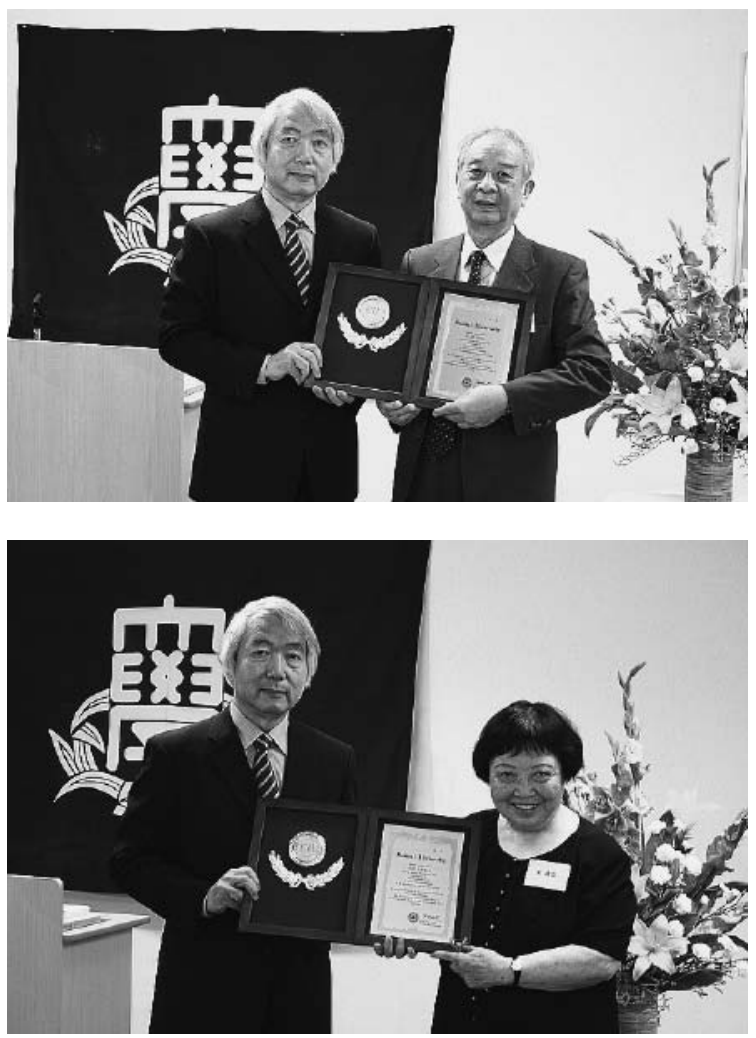

Professors Tang Yijie and Yue Daiyun received Honorary Doctorates from President Kawata Teiichi in October 2006 when Kansai University was celebrating its 120th anniversary.

Courtesy of Kansai University

(Photos by De-min Tao) 